\title{
Carnosol induces apoptosis through generation of ROS and inactivation of STAT3 signaling in human colon cancer HCT116 cells
}

\author{
KI-WOONG PARK $^{1 *}$, JUTHIKA KUNDU ${ }^{1 *}$, IN-GYEONG CHAE $^{1}$, DO-HEE KIM ${ }^{2}$, \\ MI-HEE YU ${ }^{3}$, JOYDEB KUMAR KUNDU ${ }^{1}$ and KYUNG-SOO CHUN ${ }^{1}$
}

${ }^{1}$ College of Pharmacy, Keimyung University, Daegu 704-701; ${ }^{2}$ College of Pharmacy, Seoul National University, Seoul 151-742; ${ }^{3}$ Department of Food Science and Technology, Keimyung University, Daegu 704-701, Republic of Korea

Received November 23, 2013; Accepted January 9, 2014

DOI: 10.3892/ijo.2014.2281

\begin{abstract}
Carnosol, an active constituent of rosemary, has been reported to possess anti-inflammatory and anticancer activities. However, the molecular mechanisms underlying the anticancer effects of carnosol remain poorly understood. In the present study, we found that carnosol significantly reduced the viability of human colon cancer (HCT116) cells in a concentration- and time-dependent manner. Treatment of cells with carnosol induced apoptosis, which was associated with activation of caspase- 9 and -3 and the cleavage of poly(ADP-ribose) polymerase (PARP). Incubation with carnosol elevated the expression of Bax and inhibited the levels of Bcl-2 and Bcl-xl. Carnosol induced expression of p53 and inhibited that of murine-double minute-2 (Mdm2). Moreover, carnosol generated reactive oxygen species (ROS), and pretreatment with $N$-acetyl cysteine abrogated carnosol-induced cleavage of caspase-3 and PARP. The constitutive phosphorylation, the DNA binding and reporter gene activity of signal transducer and activator of transcription-3 (STAT3) was diminished by treatment with carnosol. To further elucidate the molecular mechanisms of STAT3 inactivation, we found that carnosol attenuated the phosphorylation of Janus-activated kinase-2 (Jak2) and Src kinase. Pharmacological inhibition of Jak2 and Src inhibited STAT3 phosphorylation. Furthermore, carnosol attenuated the expression of STAT3 target gene products, such as survivin, cyclin-D1,-D2, and -D3. Taken together, our study provides the first report that carnosol induced apoptosis in HCT116 cells via generation of ROS, induction of p53, activation of caspases and inhibition of STAT3 signaling pathway.
\end{abstract}

Correspondence to: Professor Kyung-Soo Chun, College of Pharmacy, Keimyung University, 1095 Dalgubeoldaero, Dalseo-Gu, Daegu 704-701, Republic of Korea

E-mail: chunks@kmu.ac.kr

"Contributed equally

Key words: carnosol, colon cancer, apoptosis, signal transducer and activator of transcription-3, p53, reactive oxygen species

\section{Introduction}

Despite a declining trend worldwide, colorectal cancer still remains as the third most common cancer among men and the second in women $(1,2)$. More than one million new cases of colorectal cancer are diagnosed every year (3). A wide variety of natural compounds derived from edible plants have been shown to prevent colon carcinogenesis (4). Carnosol, a diterpene present in rosemary (Rosmarinus officinalis), has been reported to prevent the development of intestinal tumors in APC (adenomatous polyposis coli) mint/+ $^{\text {mice (5) }}$ and to induce apoptosis in human colon cancer (COLO 205) cells (6). However, the molecular mechanisms underlying the chemopreventive and/or chemotherapeutic effects of carnosol in colon cancer are yet to be fully elucidated. We, therefore, attempted to investigate the effects of carnosol on human colon cancer (HCT116) cells and to elucidate its underlying mechanisms.

One of the hallmarks of cancer is the evasion of tumor cells from apoptosis (7). Numerous naturally occurring polyphenols inhibit proliferation and induce apoptosis in various cancer cells (8). Apoptosis is induced by two cellular mechanisms: intrinsic (mitochondria-dependent) and extrinsic (death receptor-mediated) signaling (9). The intrinsic pathway of apoptosis involves the depolarization of mitochondrial membrane, release of cytochrome $\mathrm{c}$, sequential activation of caspase- $9,-7$ and -3 , and the cleavage of poly-(ADP-ribose) polymerase (PARP). The extrinsic pathway, on the other hand, is mediated through the activation of cell membrane-bound death receptors, followed by the activation of pro-caspase- 8 , which then execute cell death by triggering the activity of caspase-3 $(9,10)$.

Cancer cells are characterized by constitutively elevated expression of a variety of anti-apoptotic proteins and the diminished expression of pro-apoptotic proteins (11). The balance between the expression of pro- versus anti-apoptotic proteins determines the cell fate. Signal transducer and activator of transcription-3 (STAT3) is a transcription factor that transactivates the genes encoding various cell survival proteins, such as cyclins, survivin, Bcl-2 and $\mathrm{Bcl}-\mathrm{xl}(12,13)$. STAT3 is consitutively active in cancer cells, and the aberrant 
activation of STAT3-mediated signaling have been implicated in colon carcinogenesis (14-16). In response to diverse growth stimulatory signals, STAT3 gets activated through phosphorylation by upstream kinases, such as janus-activated kinase-2 (Jak2) (16) and Src tyrosine kinase (17) followed by STAT3 dimerization and nuclear localization. The blockade of STAT3 activation inhibits cell proliferation and induces apoptosis. Thus, STAT3 is a prime target of many anticancer agents (12). Herein we report, for the first time, that carnosol induces apoptosis in HCT116 cells through inactivation of STAT3 signaling pathway.

\section{Materials and methods}

Materials. Carnosol (purity 99\%), $N$-acetyl cysteine (NAC), etoposide, and $\beta$-actin antibody were purchased from Sigma-Aldrich (St. Louis, MO, USA). AG490 and PP2 were purchased from Cayman Chemical Co. (Ann Arbor, MI, USA). Antibodies against cleaved caspase-9, and -3, PARP, Bcl-2, Bcl-xl, Bax, STAT3, p-STAT3(Y705), Jak2, p-Jak2, Src, p-Src, cyclin-D1, -D2 and -D3, and survivin were procured from Cell Signaling Technology Inc. (Beverly, MA, USA). Primary antibody against each of p53, murine double minute-2 (Mdm2), Lamin-A, and horseradish peroxidase-conjugated secondary antibodies were purchased from Santa Cruz Biotechnology, Inc. (Santa Cruz, CA, USA). The 2'-7' dichlorofluorescin diacetate (DCF-DA) was procured from Invitrogen (Carlsbad, CA, USA). Hank's balanced salt solution (HBSS) was purchased from Meditech (Herndon, VA, USA). All other chemicals were of analytical or highest purity grade available.

Cell culture and treatment. HCT116 cells were obtained from American Type Culture Collections and maintained in Dulbecco's modified Eagle's medium (DMEM) supplemented with $10 \%$ fetal bovine serum and antibiotics $(100 \mathrm{U} / \mathrm{ml}$ penicillin $\mathrm{G}$ and $100 \mu \mathrm{g} / \mathrm{ml}$ streptomycin) at $37^{\circ} \mathrm{C}$ in a humidified incubator containing $5 \% \mathrm{CO}_{2}$ and $95 \%$ air. In all the experiments, cells were seeded at $2 \times 10^{5}$ cells $/ \mathrm{ml}$ and incubated with carnosol at 50-60\% confluence. All chemicals were dissolved in ethanol and the final ethanol concentration was $<1 \%$.

Cell proliferation assay. The anti-proliferative effect of carnosol against HCT116 cells was measured by using a solution of tetrazolium compound [3-(4,5-dimethylthiazol2-yl)-5-(3-carboxymethoxyphenyl)-2-(4-sulfophenyl)-

2H-tetrazolium, inner salt (MTS) (Promega, WI, USA). Briefly, cells $\left(2 \times 10^{3}\right)$ were incubated in triplicate in a 96-well plate in presence or absence of carnosol in a final volume of $0.1 \mathrm{ml}$ for different time intervals at $37^{\circ} \mathrm{C}$. Thereafter, $20 \mu \mathrm{l}$ of MTS solution was added to each well and incubated for $60 \mathrm{~min}$. The number of viable cells was measured in a 96-well plate at an optical density of $492 \mathrm{~nm}$ on a microplate reader (Tecan Trading AG, Männedorf, Switzerland). Cell viability is described as the relative percentage of control.

Annexin V staining. Annexin V staining was performed using FITC-Annexin V staining kit (BD Biosciences, San Jose, CA, USA) following the manufacturer's instructions. Briefly, carnosol-treated cells were washed with PBS and resuspended in binding buffer containing Annexin $\mathrm{V}$ and propidium iodide
(P.I.). Fluorescence intensity was measured using flow cytometry (BD Biosciences).

Western blot analysis. Cells were harvested and lysed with RIPA buffer, and collected protein samples were quantified by using bichinconinic acid protein assay kit (Pierce Biotechnology, Rockford, IL, USA). The protein samples were separated by sodium dodecyl sulfate-polyacrylamide gel electrophoresis and immunoblot analysis was done according to the protocol described earlier (18). Immunoblot membranes were incubated with Super-signal pico-chemiluminescent substrate or dura-luminol substrate (Thermo Scientific, MA, USA) according to manufacturer's instructions and visualized with ImageQuant $^{\mathrm{TM}}$ LAS 4000 (Fujifilm Life Science, Japan).

Caspase-3 activity assay. The activity of caspase-3 was detected using Caspase-3 Colorimetric Activity Assay kit (Millipore, MA, USA). The assay was performed in 96-well plates by incubating cell lysates $(50 \mu \mathrm{g})$ in $100 \mu \mathrm{l}$ reaction buffer containing caspase- 3 substrate Ac-DEVD-pNA at $37^{\circ} \mathrm{C}$ for $2 \mathrm{~h} 30 \mathrm{~min}$ following the method described earlier (18).

STAT3-Luciferase reporter gene assay. Cells were seeded into 12 -well plates at a density of $5 \times 10^{4}$ cells per well prior to transfection. Cells were transfected with p-STAT3-TAluc (Clontech, CA, USA) or control vector using Genefectin transfection reagent (Genetrone Biotech, Korea). After $24 \mathrm{~h}$ of transfection, cells were treated with carnosol for additional $24 \mathrm{~h}$ and cell lysis was carried out with $1 \mathrm{X}$ reporter lysis buffer. After mixing the cell lysates with luciferase substrate (Promega), the luciferase activity was measured by a luminometer. The $\beta$-galactosidase assay was performed according to the supplier's instructions (Promega Enzyme Assay System) for normalizing the luciferase activity and the results are expressed as fold transactivation.

Preparation of cytosolic and nuclear extracts. The cytosolic and nuclear extracts were prepared by using NE-PER Nuclear and Cytoplasmic Extraction Reagent kit (Thermo Scientific). Cells were washed with ice cold PBS, collected and centrifuged at $1,600 \mathrm{x} \mathrm{g}$ for $15 \mathrm{~min}$ at $4^{\circ} \mathrm{C}$. Pellets were suspended in $50 \mu \mathrm{l}$ of Cytoplasmic Extraction Reagent (CER)-I for $15 \mathrm{~min}$, then CERII was added for $2 \mathrm{~min}$. The mixture was centrifuged for $10 \mathrm{~min}$ at $16,000 \mathrm{x}$. Supernatant was collected as cytosolic extract. The pellets were washed with Nuclear Extraction Reagent and incubated on ice for $1 \mathrm{~h}$ and centrifuged at $16,000 \times \mathrm{g}$ for $15 \mathrm{~min}$. The supernatant containing nuclear proteins was collected and stored at $-70^{\circ} \mathrm{C}$ after determination of protein concentration by using Bradford Reagent (Bio-Rad Laboratories, Hercules, CA, USA).

Electrophoretic mobility gel shift assay (EMSA). The EMSA for STAT3 DNA binding was performed using a DNA-protein binding detection kit, according to the manufacturer's protocol (Gibco BRL, Grand Island, NY, USA). The nuclear extract was prepared from cells incubated with or without carnosol. The STAT3 oligonucleotide probe 5'-AGC TTC ATT TCC CGT AAA TCC CTA-3' (Bioneer, Korea) was labeled with $\left[\gamma^{-32} \mathrm{P}\right]-A T P$ and the EMSA was performed according to the protocol described earlier (19). 
A

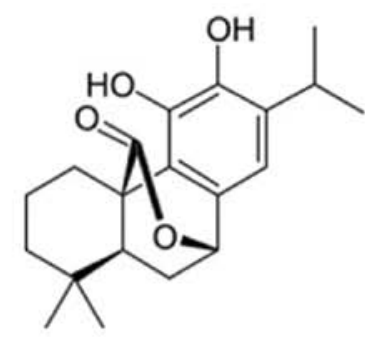

B

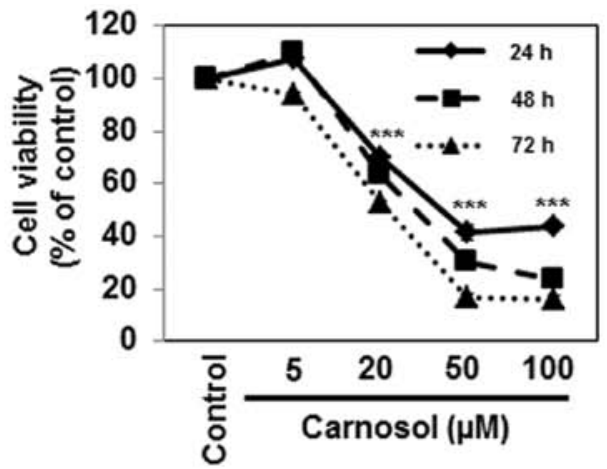

C

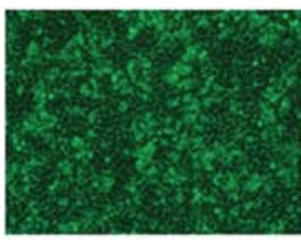

Control

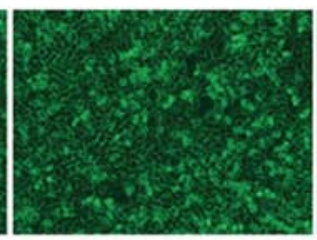

20

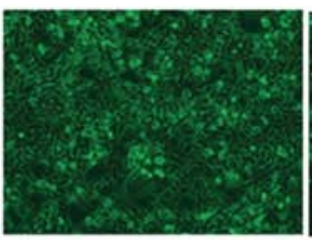

50

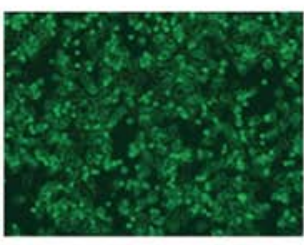

100

Carnosol $(\mu \mathrm{M})$

D
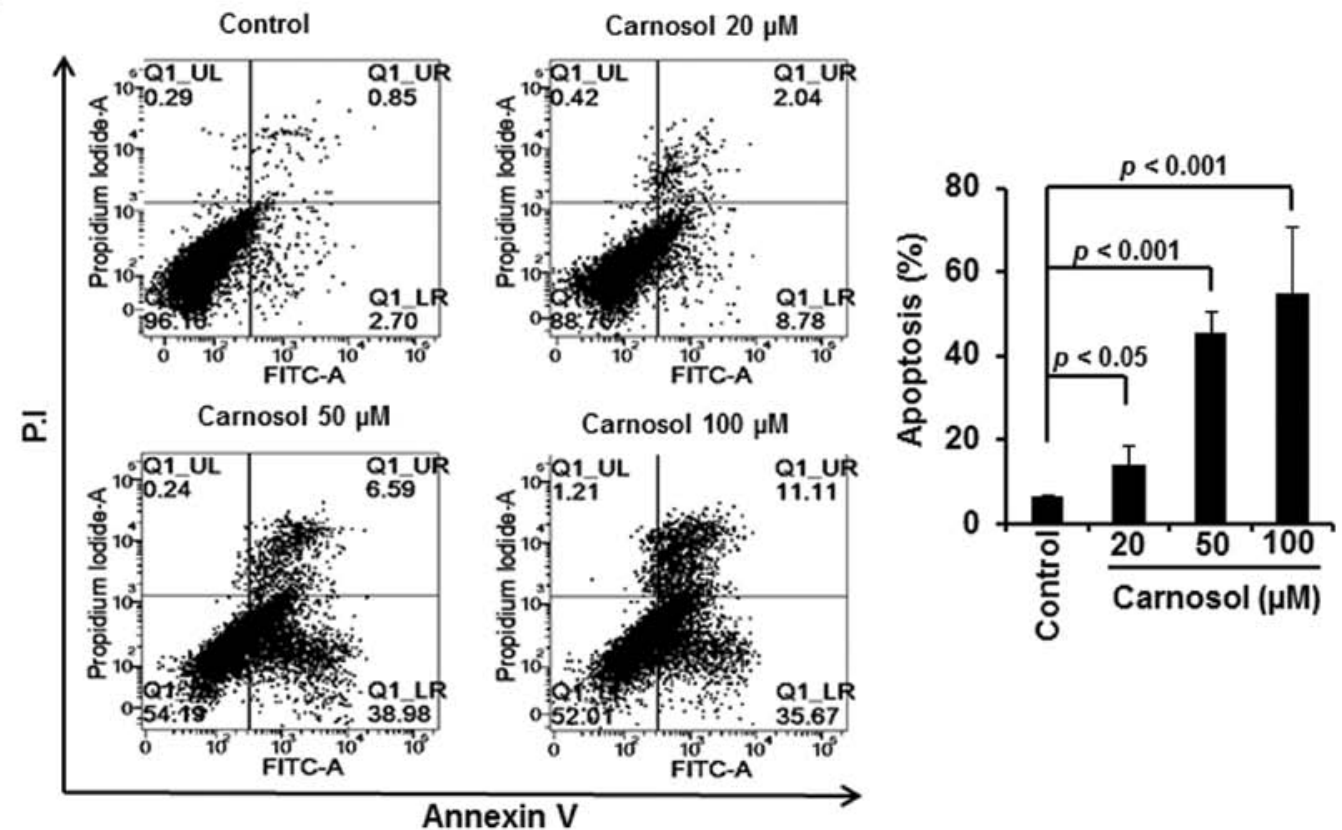

Figure 1. Cytotoxic effect of carnosol in HCT116 cells. (A) Chemical structure of carnosol. (B) HCT116 cells were treated with indicated concentrations of carnosol for 24,48 or $72 \mathrm{~h}$. Cell viability was determined by the MTS assay. Values are expressed as means \pm SD. ${ }^{* * * *}$ p $<0.001$, compared to control. (C) Cells were treated with indicated concentrations of carnosol for $24 \mathrm{~h}$ and cell morphology was analyzed by fluorescence microscopy (x200). (D) The apoptotic index (\%) was determined by flow cytometry upon treatment of cells with carnosol (20,50 or $100 \mu \mathrm{M})$ for $24 \mathrm{~h}$ and staining with Annexin V and propidium iodide (P.I). Right panel shows statistical analysis of apoptosis. Data are representative of three independent experiments.

Measurement of the accumulation of reactive oxygen species $(R O S)$. Cells were treated with carnosol in the presence or absence of NAC for $24 \mathrm{~h}$ and then loaded with $25 \mu \mathrm{M}$ of DCF-DA. After incubation for $30 \mathrm{~min}$ at $37^{\circ} \mathrm{C}$ in a $5 \% \mathrm{CO}_{2}$ incubator, cells were washed twice with HBSS solution, suspended in the complete media and were examined under a fluorescence microscope to detect the intracellular accumulation of ROS.

Statistical analysis. When necessary, data were expressed as mean \pm SD of at least three independent experiments, and statistical analysis for single comparison was performed using the Student's t-test and a p-value $<0.05$ was considered as statistically significant.

\section{Results}

Carnosol induces apoptosis in HCT116 cells. We initially examined the effect of carnosol on the viability of HCT116 cells. Incubation of cells with carnosol $(5,20,50$ or $100 \mu \mathrm{M})$ reduced the cell viability in a time- and concentrationdependent manner (Fig. 1B). Analysis of cell morphology showed that carnosol treatment induced apoptotic cell death (Fig. 1C), which was further verified by Annexin V and P.I. 
A

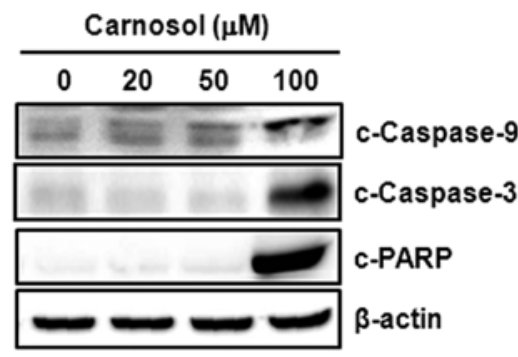

C

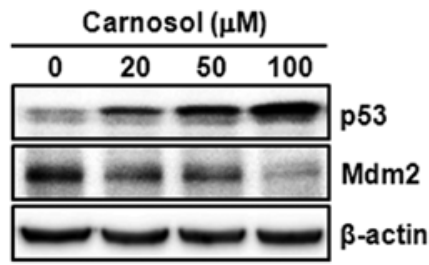

B

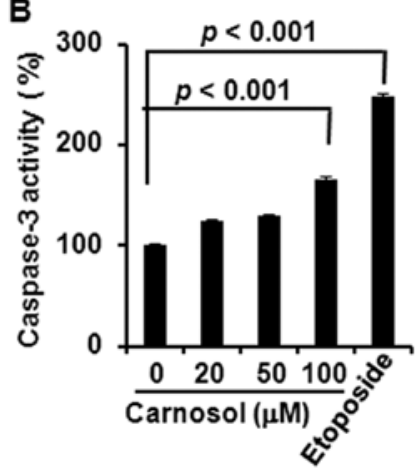

D

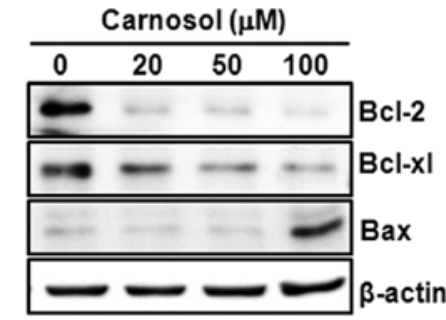

Figure 2. Effect of carnosol on cellular markers of apoptosis in HCT116 cells. Cells were treated with indicated concentrations of carnosol for $24 \mathrm{~h}$ (A) Immunoblot analysis for detecting the levels of cleaved caspase-9, and -3, and cleaved PARP. (B) After $24 \mathrm{~h}$ of incubation with carnosol (indicated concentrations) or etoposide $(85 \mu \mathrm{M})$, the caspase-3 activity assay was performed as described in Materials and methods. (C) Western blot analysis of p53 and Mdm2 expression. (D) The expression level of Bcl-2, Bcl-xl and Bax. Data are representative of three different experiments.

staining of cells treated with indicated concentrations of carnosol. As shown in Fig. 1D, carnosol induced apoptosis in a concentration-dependent manner.

Carnosol-induced apoptosis is mediated through caspase activation, p53 induction and the modulation of Bcl-2/Bax expression. Treatment of HCT116 cells with carnosol induced the cleavage of caspase-9, -3 and PARP (Fig. 2A) and increased the caspase- 3 activity, which was comparable to that of the reference compound etoposide (Fig. 2B). Incubation of cells with carnosol increased the expression of p53 and diminished the expression of $\mathrm{Mdm} 2$, that promotes p53 degradation through proteasomal degradation, in a concentration-dependent manner (Fig. 2C). Moreover, carnosol reduced the expression of anti-apoptotic protein Bcl-2, while the compound increased expression of pro-apoptotic protein Bax in HCT116 cells (Fig. 2D).

Involvement of ROS in carnosol-induced apoptosis in HCT116 cells. Since accumulation of intracellular ROS induces cell death, we examined the effect of carnosol on ROS generation. Treatment of cells with carnosol $(100 \mu \mathrm{M})$ generated ROS as revealed by immunofluorescence analysis upon DCF-DA staining (Fig. 3A) as well as by FACS analysis (Fig. 3B), which was abrogated by pretreatment of cells with NAC (Fig. 3C and D). Treatment of cells with ROS scavenger NAC abrogated carnosol-induced cleavage of caspase-3 and PARP (Fig. 3E), and the induction of apoptosis (Fig. 3F).

Carnosol attenuates the activation of STAT3 and expression of its target gene products in HCT116 cells. Since STAT3 plays a key role in cell proliferation through transcriptional activation of pro-survival genes, we examined the effect of carnosol on
STAT3 activation in HCT116 cells. Incubation with carnosol inhibited constitutive phosphorylation of STAT3 at tyrosine705 residue (Fig. 4A) and decreased the nuclear localization of phosphorylated STAT3 (Fig. 4B). Carnosol also reduced the constitutive STAT3 DNA-binding activity (Fig. 4C) and the STAT3 reporter gene activity in cells transiently transfected with STAT3-luc vector (Fig. 4D). Moreover, carnosol attenuated the expression of STAT3 target gene products, such as cyclin-D1, -D2, -D3 and survivin (Fig. 4E).

Carnosol-induced STAT3 inactivation is mediated through inhibition of Jak2 and Src phosphorylation. Several upstream kinases, such as Jak2 and Src, are known to phosphorylate STAT3 $(16,17)$. We examined the effect of carnosol on the phosphorylation of Jak2 and Src kinase. As shown in Fig. 5A, treatment with carnosol markedly diminished the phosphorylation of Jak2 and Src. To validate our findings that the inhibition of STAT3 activation by carnosol is mediated through its inhibitory effects on the constitutive phosphorylation of Jak2 and Src kinase, we incubated cells with AG490 and PP2, the pharmacological inhibitors of Jak2 and Src kinase, respectively. Treatment of cells with AG490 (Fig. 5B) or PP2 (Fig. 5C) diminished the constitutive phosphorylation of STAT3.

\section{Discussion}

Carnosol, a diterpene present in the culinary herb rosemary, has been reported to exert anticancer activities (20). However, the biochemical basis of anticancer effects of carnosol remains elusive. In the present study, we found that carnosol induced apoptosis in HCT116 cells in a time- and concentration-dependent manner. This effect of carnosol is in good agreement with the apoptosis induction by this compound in 


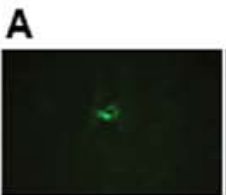

Control

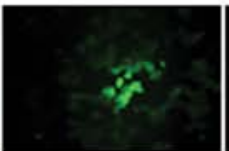

5

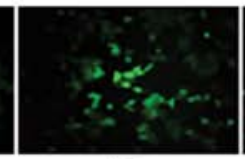

20

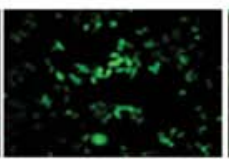

50

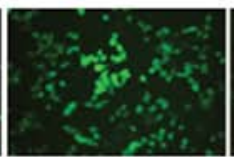

100

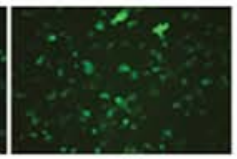

$\mathrm{H}_{2} \mathrm{O}_{2}$

Carnosol ( $\mu \mathrm{M})$

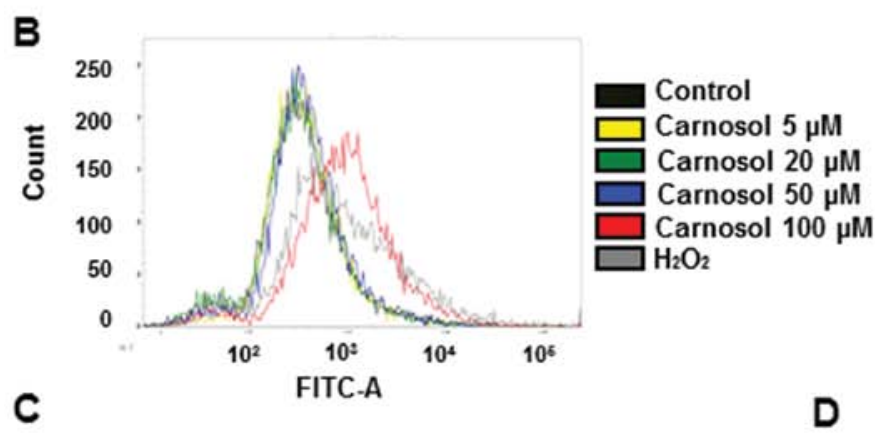

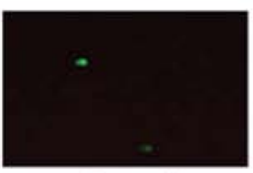

Control

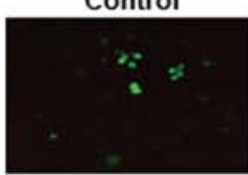

NAC + Carnosol

E
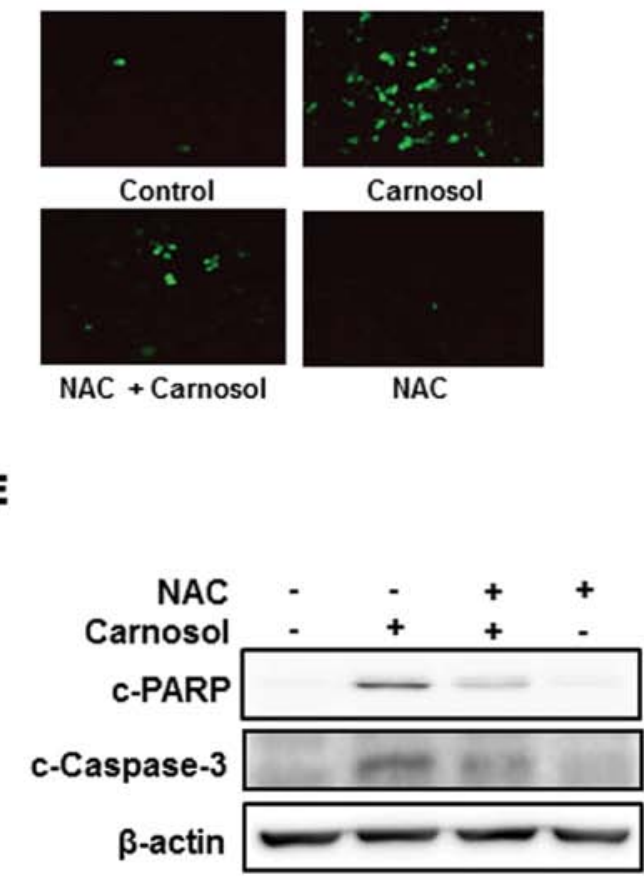

Carnosol

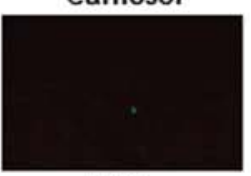

NAC

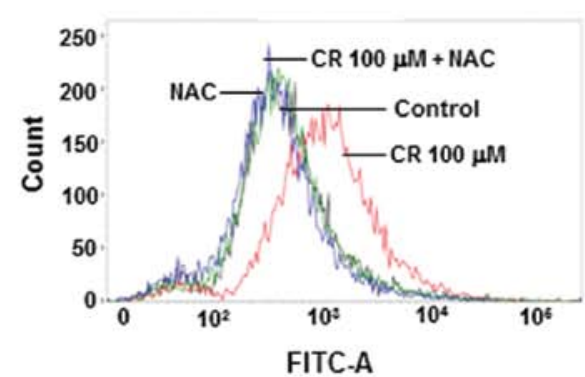

FITC-A

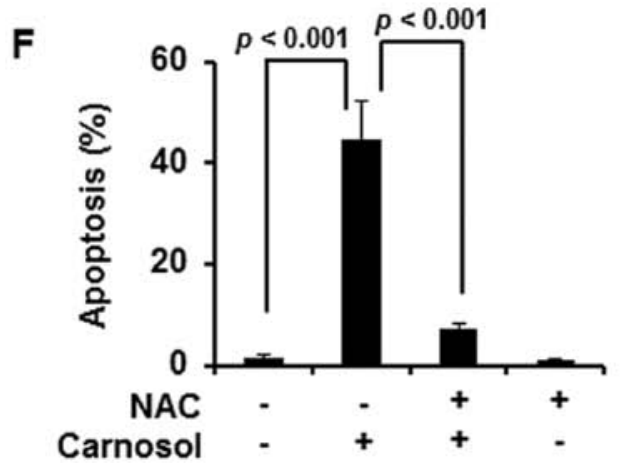

Figure 3. Involvement of ROS in carnosol-induced apoptosis in HCT116 cells. (A and B) Cells were treated with carnosol (20, 50 or $100 \mu \mathrm{M})$ for $2 \mathrm{~h}$ and then examined for the intracellular accumulation of ROS under the fluorescence microscope using DCF-DA fluorescence staining method (x200) (A) or measured by flow cytometry (B). (C and D) Cells were treated with NAC (5 mM) $1 \mathrm{~h}$ before treatment with carnosol (100 $\mu \mathrm{M})$ for $2 \mathrm{~h}$. ROS levels were measured either by fluorescence microscopy (C) or by flow cytometry (D). The experiment was done in triplicate and the data presented as mean \pm SD. (E and F) Cells were treated with carnosol $(100 \mu \mathrm{M})$ for $24 \mathrm{~h}$ after pre-incubation with or without NAC $(5 \mathrm{mM})$ for $1 \mathrm{~h}$. (E) Levels of cleaved PARP and caspase-3 were detected by western blot analysis. (F) Percent apoptosis index was measured by Annexin V staining. Data are representative of three independent experiments.

other cancer cells $(21,22)$, including that in COLO 205 colon cancer cells (6). Then we attempted to delineate the molecular mechanisms of anticancer effects of carnosol. The cleavage of pro-caspase- 9 by carnosol resulted in the activation of effector caspase- 3 and the cleavage of PARP. Since caspase-9 is an initiator caspase in mitochondria-mediated death signaling (9), these findings suggest that carnosol may induce apoptosis through the intrinsic pathway.

Cells are equipped with a series of anti-apoptotic (e.g., Bcl-2, Bcl-xl) and apoptosis-inducing proteins (e.g., Bax, p53). Overexpression of Bcl-2 or Bcl-xl inhibits apoptosis and promotes survival of cells (23). According to Zhu et al, the induction of Bax is essential for death receptor-mediated apoptosis in human colon cancer cells (24). On the other hand, the pro-survival protein $\mathrm{Bcl}-2$ is overexpressed in colon cancer (25) and the Bcl-2-mediated inhibition of apoptosis restores the tumorigenecity of spontaneously regressed colon tumors in vivo (26). The inhibition of Bcl-2 and Bcl-xl expression and the increase in Bax protein level, thus, provide a mechanistic basis of apoptosis induction by carnosol.

p53, an apoptosis-inducing protein (27), undergoes proteasomal degradation by its cytosolic repressor Mdm2 (28). 
A

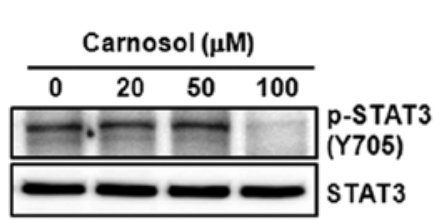

B

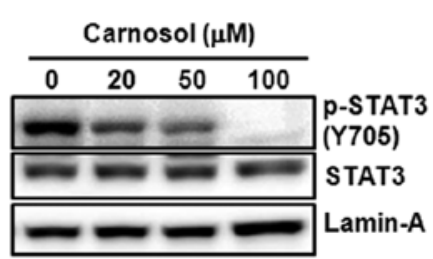

c

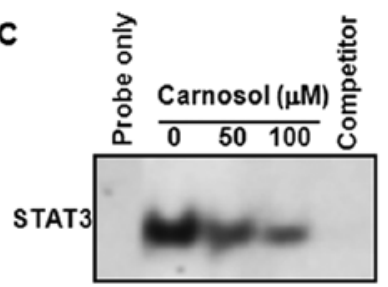

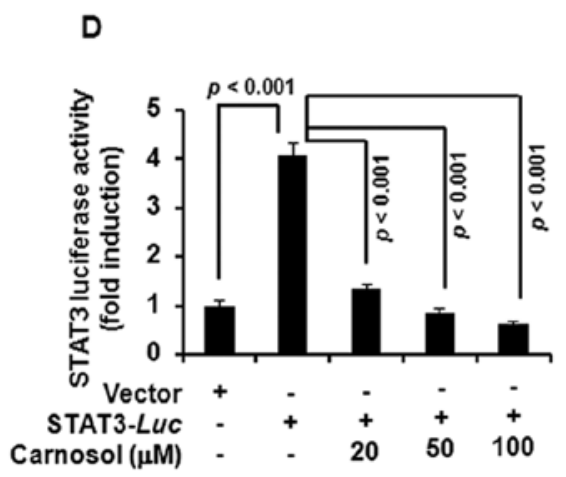

$\mathbf{E}$

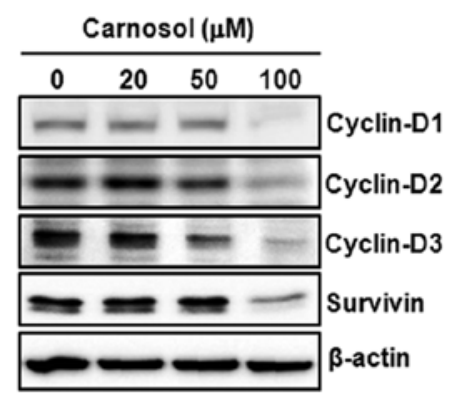

Figure 4. Carnosol inhibits constitutive activation of STAT3 and expression of its gene products. (A) Cells were treated with indicated concentrations of carnosol and the level of p-STAT3(Y705) was detected by immunoblotting. (B and C) Nuclear extract prepared from cells treated with carnosol as indicated and was assessed for (B) nuclear accumulation of p-STAT3(Y705) and (C) the DNA-binding of STAT3. (D) Cells transfected with STAT3-luc construct were incubated with carnosol $(20,50$ or $100 \mu \mathrm{M})$ for $24 \mathrm{~h}$. The luciferase activity was measured as described in Materials and methods. (E) Cells were treated with indicated concentrations of carnosol for $24 \mathrm{~h}$. Immunoblot analysis was performed to assess the expression of cyclin-D1, -D2 and -D3, and survivin.
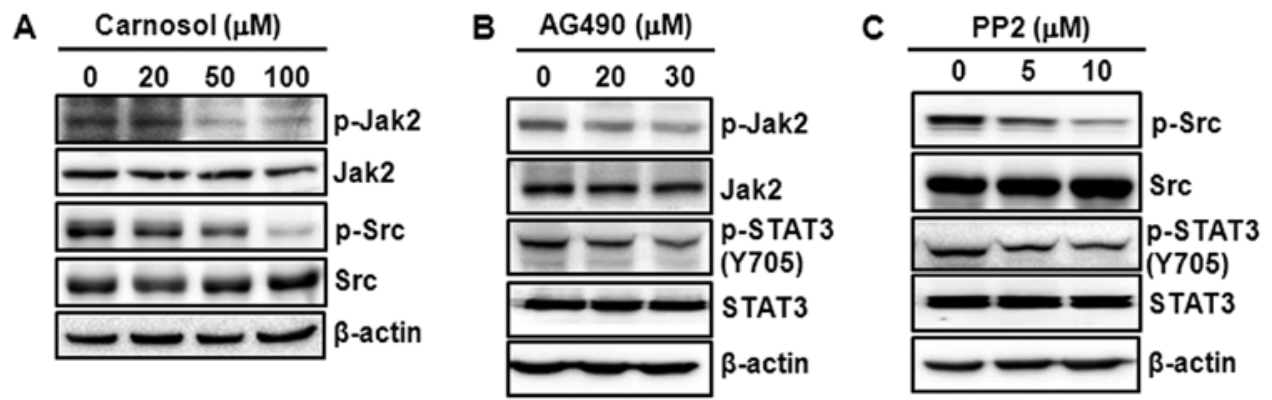

Figure 5. Carnosol inhibits the phosphorylation of Jak2 and Src kinase in HCT116 cells. Cells were incubated with indicated concentrations of carnosol for $24 \mathrm{~h}$. (A) Immunoblot analysis was performed to assess the expression of p-Jak2 and p-Src. (B) Cells were treated with indicated concentrations of AG490 for $24 \mathrm{~h}$ and the expression of p-Jak2 and p-STAT3(Y705) was examined. (C) Upon treatment with PP2 for $24 \mathrm{~h}$, cell lysates were subjected to immunoblot analysis for the detection of p-Src and p-STAT3(Y705).

Pharmacological inhibition of Mdm2 activates p53 and induces growth arrest in mouse colon tumor and human colon cancer cells (29). The inhibition of Mdm2 expression and concomitant increase in p53 expression by carnosol, thus, suggest that carnosol may induce apoptosis by inducing p53 expression. While the pro-apoptotic Bax gene is a direct target of p53 (30), the overexpression of p53 in p53-null cells diminish Bcl-2 expression (31). Thus, carnosol-induced p53 activation may result in cell death through downregulation of Bcl-2 and upregulation of Bax. Since the induction of $\mathrm{p} 53$ occurs in response to oxidative stress (32), we examined if carnosol generates ROS in HCT116 cells. We found that carnosol induced ROS generation, which was diminished by ROS scavenger NAC. Moreover, pretreatment of cells with NAC attenuated carnosol-induced cleavage of caspase-3 and PARP. Thus, carnosol-induced ROS generation may activate $\mathrm{p} 53$, resulting in the downregulation of $\mathrm{Bcl}-2$ and induction of Bax expression, thereby leading to the activation of caspases and induction of apoptosis.
Apart from the regulation by $\mathrm{p} 53$, the expression of anti-apoptotic proteins $\mathrm{Bcl}-2$ and $\mathrm{Bcl}-\mathrm{xl}$ is also regulated by STAT3 (13), which is overexpressed in colon cancer (12). Persistent STAT3 activation increases the proliferation of colon cancer cells in culture and enhances the growth of colon cancer cell xenograft tumors in nude mice (33). Moreover, the inhibition of STAT3 signaling induces apoptosis and cell cycle arrest in colon carcinoma cells (34). Therefore, we examined the effect of carnosol on STAT3 signaling in HCT116 cells. STAT3 activation mechanism involves the phosphorylation of its tyrosine 705 residue followed by the formation of STAT3 dimer, which translocates to the nucleus and interacts with the promoter region of target genes (12). Several upstream kinases including Jak2 (16) and Src (17) have been reported to phosphorylate STAT3 at tyrosine705 residue. The decreased phosphorylation of STAT3, Jak2 and Src kinase by carnosol suggests that the apoptosis induction by this compound is mediated through inhibition of STAT3 signaling. This was further supported by the findings that carnosol diminished STAT3 
DNA binding and STAT3-reporter gene activity, thereby reducing the expression of D-series cyclins and survivin, which are STAT3 target gene products $(13,35)$. While, survivin inhibits Fas-mediated apoptosis in cancer cells (36), cyclins promote cell proliferation (15). Thus, the reduced expression of survivin and D-series cyclins by carnosol is associated with the induction of apoptosis by this compound.

In conclusion, our study demonstrates for the first time that carnosol-induced generation of ROS, activation of caspases, induction of p53 and the inhibition of STAT3 signaling lead to the induction of apoptosis in HCT116 cells, which may provide a mechanistic basis of the anticancer activity of the compound.

\section{Acknowledgements}

This study was supported by the College of Pharmacy-specialized Research Fund (the Institute for New Drug Development) of Keimyung University in 2013.

\section{References}

1. Jemal A, Center MM, DeSantis C and Ward EM: Global patterns of cancer incidence and mortality rates and trends. Cancer Epidemiol Biomarkers Prev 19: 1893-1907, 2010.

2. Jemal A, Siegel R, Xu J and Ward E: Cancer statistics, 2010. CA Cancer J Clin 60: 277-300, 2010.

3. Merika E, Saif MW, Katz A, Syrigos K and Morse M: Review. Colon cancer vaccines: an update. In Vivo 24: 607-628, 2010.

4. Chung MY, Lim TG and Lee KW: Molecular mechanisms of chemopreventive phytochemicals against gastroenterological cancer development. World J Gastroenterol 19: 984-993, 2013.

5. Moran AE, Carothers AM, Weyant MJ, Redston M and Bertagnolli MM: Carnosol inhibits beta-catenin tyrosine phosphorylation and prevents adenoma formation in the C57BL/6J/ Min/+ (Min/+) mouse. Cancer Res 65: 1097-1104, 2005.

6. Cheng AC, Lee MF, Tsai ML, et al: Rosmanol potently induces apoptosis through both the mitochondrial apoptotic pathway and death receptor pathway in human colon adenocarcinoma COLO 205 cells. Food Chem Toxicol 49: 485-493, 2011.

7. Hanahan D and Weinberg RA: Hallmarks of cancer: the next generation. Cell 144: 646-674, 2011

8. Neergheen VS, Bahorun T, Taylor EW, Jen LS and Aruoma OI Targeting specific cell signaling transduction pathways by dietary and medicinal phytochemicals in cancer chemoprevention. Toxicology 278: 229-241, 2010.

9. Burz C, Berindan-Neagoe I, Balacescu O and Irimie A: Apoptosis in cancer: key molecular signaling pathways and therapy targets Acta Oncol 48: 811-821, 2009.

10. Martin SJ and Green DR: Protease activation during apoptosis: death by a thousand cuts? Cell 82: 349-352, 1995.

11. Aggarwal BB, Takada Y and Oommen OV: From chemoprevention to chemotherapy: common targets and common goals Expert Opin Investig Drugs 13: 1327-1338, 2004.

12. Johnston PA and Grandis JR: STAT3 signaling: anticancer strategies and challenges. Mol Interv 11: 18-26, 2011.

13. Masuda M, Suzui M, Yasumatu R, et al: Constitutive activation of signal transducers and activators of transcription 3 correlates with cyclin D1 overexpression and may provide a novel prognostic marker in head and neck squamous cell carcinoma. Cancer Res 62: 3351-3355, 2002.

14. Lau GK and Ye D: STAT3 implicated in the development of colon cancer: a step closer for targeted therapy? Gastroenterology 139: 353-355, 2010.

15. Lin L, Liu A, Peng Z, et al: STAT3 is necessary for proliferation and survival in colon cancer-initiating cells. Cancer Res 71 7226-7237, 2011.

16. Slattery ML, Lundgreen A, Kadlubar SA, Bondurant KL and Wolff RK: JAK/STAT/SOCS-signaling pathway and colon and rectal cancer. Mol Carcinog 52: 155-166, 2013.
17. Laird AD, Li G, Moss KG, et al: Src family kinase activity is required for signal tranducer and activator of transcription 3 and focal adhesion kinase phosphorylation and vascular endothelial growth factor signaling in vivo and for anchorage-dependent and -independent growth of human tumor cells. Mol Cancer Ther 2: 461-469, 2003.

18. Kundu J, Wahab SM, Kundu JK, et al: Tob1 induces apoptosis and inhibits proliferation, migration and invasion of gastric cancer cells by activating Smad4 and inhibiting beta-catenin signaling. Int J Oncol 41: 839-848, 2012.

19. Kundu JK, Shin YK, Kim SH and Surh YJ: Resveratrol inhibits phorbol ester-induced expression of COX-2 and activation of NF-kappaB in mouse skin by blocking IkappaB kinase activity. Carcinogenesis 27: 1465-1474, 2006.

20. Johnson JJ: Carnosol: a promising anti-cancer and antiinflammatory agent. Cancer Lett 305: 1-7, 2011.

21. Dorrie J, Sapala K and Zunino SJ: Carnosol-induced apoptosis and downregulation of Bcl-2 in B-lineage leukemia cells. Cancer Lett 170: 33-39, 2001.

22. Johnson JJ, Syed DN, Heren CR, Suh Y, Adhami VM and Mukhtar H: Carnosol, a dietary diterpene, displays growth inhibitory effects in human prostate cancer PC3 cells leading to G2-phase cell cycle arrest and targets the 5'-AMP-activated protein kinase (AMPK) pathway. Pharm Res 25: 2125-2134, 2008.

23. Cherbonnel-Lasserre C and Dosanjh MK: Suppression of apoptosis by overexpression of Bcl-2 or Bcl-xL promotes survival and mutagenesis after oxidative damage. Biochimie 79: 613-617, 1997.

24. Zhu S, Li T, Tan J, et al: Bax is essential for death receptormediated apoptosis in human colon cancer cells. Cancer Biother Radiopharm 27: 577-581, 2012.

25. Valassiadou KE, Stefanaki K, Tzardi M, et al: Immunohistochemical expression of $\mathrm{p} 53, \mathrm{bcl}-2, \mathrm{mdm} 2$ and waf $1 / \mathrm{p} 21$ proteins in colorectal adenocarcinomas. Anticancer Res 17: 2571-2576, 1997.

26. Bonnotte B, Favre N, Moutet M, et al: Bcl-2-mediated inhibition of apoptosis prevents immunogenicity and restores tumorigenicity of spontaneously regressive tumors. J Immunol 161: 1433-1438, 1998.

27. Shaw P, Bovey R, Tardy S, Sahli R, Sordat B and Costa J: Induction of apoptosis by wild-type $\mathrm{p} 53$ in a human colon tumorderived cell line. Proc Natl Acad Sci USA 89: 4495-4499, 1992.

28. Kim DH, Kundu JK and Surh YJ: Redox modulation of p53: mechanisms and functional significance. Mol Carcinog 50: 222-234, 2011.

29. Rigatti MJ, Verma R, Belinsky GS, Rosenberg DW and Giardina C: Pharmacological inhibition of $\mathrm{Mdm} 2$ triggers growth arrest and promotes DNA breakage in mouse colon tumors and human colon cancer cells. Mol Carcinog 51: 363-378, 2012

30. Miyashita T and Reed JC: Tumor suppressor p53 is a direct transcriptional activator of the human bax gene. Cell 80: 293-299, 1995.

31. Miyashita T, Krajewski S, Krajewska M, et al: Tumor suppressor p53 is a regulator of bcl-2 and bax gene expression in vitro and in vivo. Oncogene 9: 1799-1805, 1994

32. Lotem J, Peled-Kamar M, Groner Y and Sachs L: Cellular oxidative stress and the control of apoptosis by wild-type p53, cytotoxic compounds, and cytokines. Proc Natl Acad Sci USA 93: 9166-9171, 1996

33. Corvinus FM, Orth C, Moriggl R, et al: Persistent STAT3 activation in colon cancer is associated with enhanced cell proliferation and tumor growth. Neoplasia 7: 545-555, 2005.

34. Lin Q, Lai R, Chirieac LR, et al: Constitutive activation of JAK3/ STAT3 in colon carcinoma tumors and cell lines: inhibition of JAK3/STAT3 signaling induces apoptosis and cell cycle arrest of colon carcinoma cells. Am J Pathol 167: 969-980, 2005.

35. Kanda N, Seno H, Konda Y, et al: STAT3 is constitutively activated and supports cell survival in association with survivin expression in gastric cancer cells. Oncogene 23: 4921-4929, 2004.

36. Asanuma K, Tsuji N, Endoh T, Yagihashi A and Watanabe N: Survivin enhances Fas ligand expression via up-regulation of specificity protein 1-mediated gene transcription in colon cancer cells. J Immunol 172: 3922-3929, 2004 